\title{
Development of the edible blend films with good mechanical and barrier properties from pea starch and guar gum
}

Saberi, Bahareh, Thakur, Rahul, Bhuyan, Deep Jyoti, Vuong, Quan V., Chockchaisawasdee, Suwimol, Golding, John B., Scarlett, Christopher J., Stathopoulos, Costas E.

This is the peer reviewed version of the following article:

Saberi, B. et al. 2016. Development of the edible blend films with good mechanical and barrier properties from pea starch and guar gum. Starch.

which has been published in final form at doi: https://dx.doi.org/10.1002/star.201600227

This article may be used for non-commercial purposes in accordance with the Wiley Terms and Conditions for Self-Archiving 
Development of the edible blend films with good mechanical and barrier properties from pea starch and guar gum

Bahareh Saberi', Rahul Thakurl, Deep Jyoti Bhuyan ${ }^{1}$, Quan V. Vuong', Suwimol Chockchaisawasdee $^{1}$, John B. Golding ${ }^{1,2}$, Christopher J. Scarlett ${ }^{1 *}$, Costas E. Stathopoulos ${ }^{3 *}$

${ }^{1}$ School of Environmental and Life Sciences, University of Newcastle, Ourimbah, NSW 2258, Australia

${ }^{2}$ NSW Department of Primary Industries, Ourimbah, NSW 2258, Australia

${ }^{3}$ Division of Food and Drink, School of Science, Engineering and Technology, University of Abertay, Dundee DD1 1HG, UK

\section{*Correspondence to:}

Christopher J. Scarlett

School of Environmental and Life Sciences, Faculty of Science and Information Technology, University of Newcastle, Brush Road, Ourimbah, NSW 2258, Australia.

Tel: +61 243484680; Fax: +61 24348 4145; E-mail: c.scarlett@newcastle.edu.au

Costas E. Stathopoulos

Division of Food and Drink, School of Science, Engineering and Technology, University of Abertay, Dundee DD1 1HG, UK.

Tel: +44 (0)1382 308481; E-mail: c.stathopoulos@abertay.ac.uk

Keywords: Pea starch; Guar gum; Edible films; Mechanical properties; Response surface methodology 


\section{ABSTRACT}

The individual and interactive impacts of guar gum and glycerol on the pea starch-based edible film characteristics were examined using three factors with three level Box-Behnken response surface design. The results showed that density and elongation at break were only significantly ( $p$ $<0.05)$ affected by pea starch and guar gum in a positive linear fashion. The quadratic regression coefficient of pea starch showed a significant effect $(p<0.05)$ on thickness, density, puncture force, water vapour permeability, and tensile strength. While tensile strength and Young modulus affected by the quadratic regression coefficient of glycerol and guar gum, respectively. The results were analysed using Pareto analysis of variance (ANOVA) and the developed predictive equations for each response variable presented reliable and satisfactory fit with high coefficient of determination $\left(\mathrm{R}^{2}\right)$ values $(\geq 0.96)$. The optimized conditions with the goal of maximizing mechanical properties and minimizing water vapour permeability were $2.5 \mathrm{~g}$ pea starch, $0.3 \mathrm{~g}$ guar gum and $25 \%(\mathrm{w} / \mathrm{w})$ glycerol based on the dry film matter in $100 \mathrm{ml}$ of distilled water. Generally, changes in the concentrations of pea starch, guar gum and glycerol resulted in changes in the functional properties of film.

Keywords: Pea starch; Guar gum; Edible films; Mechanical properties; Response surface methodology 


\section{Introduction}

The application of biodegradable resources with characteristics that ensure food safety along with decreasing the environmental impacts has gained a significant amount of interest worldwide [1]. Contrary to synthetic polymers, materials made from polysaccharides are commonly eco-friendly because they can undergo disintegration without environmentally damaging remainders [2]. Since polysaccharides are mostly available in nature and are known as structural substances, they have been regarded as proper alternatives for biodegradable films [3].

Starch has the capability to be used for edible films production because it can produce tasteless, odorless and transparent films with similar properties to synthetic polymers [4]. However, starch edible films generally show poor mechanical strength and high moisture sensitivity [5]. To overcome these drawbacks, studies on different additives, sources of starch, various modifications, and process factors have been conducted [6-9]. The physical and functional characteristics of starch films can be improved by combining with other biopolymers, hydrophobic materials, and antioxidant/antimicrobial compounds [10-13]. The blending of starch and other hydrocolloids has been shown to modify the mechanical properties of the resultant film [9], which depends on the compatibility/incompatibility of binary polymeric blends [9, 14]. Moreover, incorporation of hydrocolloids in starch edible films results in increasing viscosity of starch systems [9, 15] and decreasing their retrogradation rate [16]. Interactions between starch and other hydrocolloids are determined by their molecular weight, chemical structures, conformations and hydration behaviors [14]. 
Recent studies have investigated the effect of the incorporation of hydrocolloids on physical and mechanical properties of different starch films. It has been indicated that the incorporation of the xanthan gum (0 to $0.1 \% \mathrm{w} / \mathrm{w})$ to cassava starch $(3-5 \%)$ did not show a considerable impact on either the mechanical properties or on the water absorption kinetics of films [17]. Bangyekan, AhtOng and Srikulkit [18] reported that the water vapor permeability (WVP) of cassava starch films was reduced with increasing chitosan concentration and increased with increasing in glycerol content. Lafargue, Lourdin and Doublier [19] studied the combination of hydroxypropylated pea starch with $\kappa$-carrageenan to make edible films. They showed an improvement in film drying and formation, without any changes in its properties. Chillo, Flores, Mastromatteo, Conte, Gerschenson and Del Nobile [20] observed that the mechanical properties of tapioca starch films improved by incorporation of chitosan. While, water vapor permeability and mechanical strength and elongation of tapioca starch films increased by addition of hsian-tsao leaf gum [21]. da Matta, Sarmento, de Oliveira and Zocchi [22] found that the addition of xanthan gum to the green pea starch with high content of amylose ( $c v$. Utrillo), had no effect on mechanical properties of the films. The association of agar to maize starch films increased the transparency, thickness and WVP of the obtained films [4].

We have previously demonstrated that incorporation of guar gum and pea starch resulted in biocomposite edible films with improved physical and optical properties [23]. However, to the best of our knowledge, there is no specific study on the effect of blending guar gum on mechanical and barrier properties of pea starch edible films. Guar gum is derived from the endosperm of an annual legume plant Cyamopsis tetragonoloba, which is grown mainly in India and Pakistan and to a smaller extent in Australia, Africa and United States, is a type of galactomannan [24]. Seed galactomannans from various legume plants have some common structural properties, though they 
vary noticeably in their molecular weight, ratio of the component sugars (mannose-to-galactose ratio, or $\mathrm{M}: \mathrm{G})$, the specific location of single galactose residues on the linear mannose backbone in their molecule, and their functional characteristics [25]. There are a number of galactomannans used industrially, namely tara gum with a $\mathrm{M} / \mathrm{G}$ ratio of $3: 1$, locust bean gum with an $\mathrm{M} / \mathrm{G}$ ratio of $4: 1[26,27]$ and fenugreek gum with an $M / G$ ratio of $1: 1$. According to these ratios guar gum is most similar to fenugreek gum. Guar gum is a linear galactomannan, the molecule of which is composed of a $\beta(1 \rightarrow 4)$-linked mannopyranose backbone, with several its branch points (grafts) from the C-6 position of mannopyranose, linked by $\alpha(1 \rightarrow 6)$ bond to a single D-galactopyranose sugar [28]. It has many applications owing to low cost and many distinctive characteristics including biodegradability, biocompatibility and non-toxicity [24]. Owing to long polymeric chain, high molecular weight and wide availability of guar gum, it is a potential alternative for the development of a renewable source based biodegradable packaging material as in comparison with other biopolymers [29]. Very few reports exist on guar gum based biodegradable packaging films $[23,29-32]$.

Therefore, the aim of the present work was to develop a biocomposite edible film by combining pea starch and guar gum and assessing the effect of different ratios of these polysaccharides on barrier and mechanical properties of the film using response surface methodology (RSM) analysis.

\section{Materials and methods}

\subsection{Materials}

Canadian non-GMO yellow pea starch with $13.2 \%$ moisture, $0.2 \%$ protein, $0.5 \%$ fat, $0.3 \%$ ash and $36.25 \pm 0.32 \%$ amylose, was used in all experiments (supplied by Yantai Shuangta Food Co., Jinling Town, China). Guar gum (E-412) was purchased from The Melbourne Food Ingredient 
Depot, Brunswick East, Melbourne, Australia. All other chemicals were purchased from Merck Millipore Pty. Ltd., Victoria, Australia.

\subsection{Films preparation}

The film-forming solution was prepared by dissolving pea starch (2-3 g) and guar gum (0.1-0.5 g) in $100 \mathrm{ml}$ degassed deionized water with gentle heating (about $40{ }^{\circ} \mathrm{C}$ ) and magnetic stirring, followed by addition of $15 \%, 25 \%$, and $35 \%$ glycerol based on the dry film matter. The dispersion was then heated at $90{ }^{\circ} \mathrm{C}$ for 20 min with gentle magnet stirring to allow complete gelatinization of the starch. After gelatinization, the film solution was cooled to room temperature with gentle magnetic stirring for $1 \mathrm{~h}$ to reduce air bubbles. All the films were prepared by casting method where $20 \mathrm{~g}$ of filmogenic suspensions were poured onto Petri dishes $(10 \mathrm{~cm}$ in diameter). Films were formed by drying at $40{ }^{\circ} \mathrm{C}$ in an oven until reaching constant weight (about $24 \mathrm{~h}$ ). The prepared films were peeled-off from Petri dishes and equilibrated at $25^{\circ} \mathrm{C}, 65 \%$ relative humidity for $72 \mathrm{~h}$ prior to further examination [33].

\subsection{Film thickness and density}

A digital micrometer (Mitutoyo Corp., Code No. 543-551-1, Model ID-F125, Japan) was used to determine the thickness (THI) of the films. Ten measurements were randomly taken at different locations for each specimen and the mean value was reported and used in the calculations of the mechanical properties and water vapor permeability. Film density (D) was evaluated by dividing the film weight by the film volume, where the film volume was calculated by multiplying the film area by the thickness [34].

\subsection{Water vapor permeability}


The water vapor transmission of the films was determined gravimetrically according to the ASTM E96 procedure [35] with a $75 \% \mathrm{RH}$ gradient at $25^{\circ} \mathrm{C}$. Permeation cells containing anhydrous $\mathrm{CaCl}_{2}$ $(0 \% \mathrm{RH})$ were sealed by the test film $\left(0.7065 \mathrm{~mm}^{2}\right.$ film area) using melted paraffin (leaving an air gap of $1 \mathrm{~cm}$ between the film and the desiccant). To keep a 75\% RH gradient across the film, a saturated $\mathrm{NaCl}$ solution $(75 \% \mathrm{RH})$ was used in the desiccators. The RH inside the cell was always lower than outside, and water vapor transport was determined using the weight gain of the cell at a steady state of transfer. Changes in the weight of the cell were recorded to the nearest $0.0001 \mathrm{~g}$ and plotted as a function of time. The slope of each line was evaluated by linear regression $\left(\mathrm{r}^{2}>\right.$ 0.99), and the water vapor transmission rate was calculated through the slope of the straight line $(\mathrm{g} / \mathrm{s})$ divided by the test area $\left(\mathrm{m}^{2}\right)$. All values for water vapor transmission rate (WVTR) were corrected for air-gap distance between the calcium chloride and the film surface according to the equations of Gennadios, Weller and Gooding [36]:

$\mathrm{WVTR}=\frac{\text { slope }}{\text { film area }}=\frac{\Delta m}{\Delta t \times A}$

After the permeation tests, the film thickness was measured and water vapor permeability (WVP) $\left(\mathrm{g} \mathrm{Pa}^{-1} \mathrm{~s}^{-1} \mathrm{~m}^{-1}\right)$ was calculated as:

$\mathrm{WVP}=\frac{\Delta m}{A \Delta t} \frac{X}{\Delta P}$

where $\Delta \mathrm{m} / \Delta \mathrm{t}$ is the weight of moisture gain per unit of time $(\mathrm{g} / \mathrm{s}), \mathrm{X}$ is the average film thickness $(\mathrm{mm}), \mathrm{A}$ is the area of the exposed film surface $\left(\mathrm{m}^{2}\right)$, and $\Delta \mathrm{P}$ is the water vapor pressure difference between the two sides of the film $(\mathrm{Pa})$. WVP was measured for three replicated samples for each type of film [37].

\subsection{Mechanical tensile test}


The mechanical properties of the films were determined using a Texture Analyzer (LLOYD Instrument LTD, Fareham, UK) according to ASTM standard method D882-00 [38]. Eight film specimens $(40 \mathrm{~mm} \times 15 \mathrm{~mm})$ of each formulation were used for mechanical tests and fixed between the grips of the machine. The maximum load $(\mathrm{N})$ and extension $(\mathrm{mm})$ curves were recorded to calculate tensile strength (TS), percent elongation at break (\% E) and Young Modulus (YM) at break of the films using a tensile test at crosshead speed of $1 \mathrm{~mm} / \mathrm{s}$ and initial grip distance $40 \mathrm{~mm}$ [37].

\subsection{Mechanical puncture test}

The puncture test was performed to realize the mechanical resistibility of films under sharp stress by using a Texture Analyzer (LLOYD Instrument LTD, Fareham, UK). Films were cut into a 4 $\mathrm{cm}$-diameter disk and fixed in an annular ring clamp (3 cm diameter). A spherical probe of $1.0 \mathrm{~mm}$ diameter was moved vertically to the film surface at a constant speed of $1 \mathrm{~mm} / \mathrm{s}$ until the probe passed through the film, and force-deformation curves were plotted. Force $(\mathrm{N})$ and deformation $(\mathrm{mm})$ values at the puncture point were then recorded to represent the puncture force $(\mathrm{PF})(\mathrm{N})$ and deformation (PD) (mm) of the films. For each sample, eight replicates were performed [37].

\subsection{Experimental design}

The effect of process parameters (pea starch (X1): 2-3 g, glycerol (X2): 15-35\%, and guar gum (X3): $0.1-0.5 \mathrm{~g}$ on film properties (Table 1) was studied by applying a three-level-three-factor, Box-Behnken response surface design (BBD) with five central point replicates. The preliminary single factor tests were performed to select the optimum levels of the independent variables (data are not shown). All experimental runs are listed in Table 2. The experimental data obtained for the seventeen experimental runs were fitted to the following second-order polynomial model: 
$\mathrm{Y}=\beta_{0}+\sum_{i=1}^{k} \beta_{i} X_{i}+\sum_{i=1}^{k-1} \sum_{j=2}^{k} \beta_{i j} X_{i} X_{j}+\sum_{i=1}^{k} \beta_{i i} X_{i}^{2}+e_{i}$

where various $X_{i}$ values are independent variables affecting the responses $Y ; \beta_{0}, \beta_{i}, \beta_{i i}$, and $\beta_{i j}$ are the regression coefficients for intercept, interaction coefficients of linear, quadratic and the secondorder terms, respectively and $\mathrm{k}$ is the number of variables [39].

\subsection{Statistical analysis}

The model equations, the 3D- and 2D contour plots of variable responses and the optimum values for the three independent variables were established by JMP software (Version 11, SAS, Cary, $\mathrm{NC}$, USA). The lack of fit and the coefficient of determination $\left(\mathrm{R}^{2}\right)$ confirmed the adequacy of the response surface methodology (RSM) second-order polynomial model. Statistical software of Statistical Package for Social Science 16 (SPSS, Inc., Upper Saddle River, NJ) was used to separate the means analysis by independent samples $t$-test. The differences between the mean values in the achieved experiments were taken to be statistically significant at $p<0.05$.

\section{Results and discussion}

\subsection{Fitting the response surface methodology model}

According to the Box-Behnken experimental design, fitting the models was performed in this study to decide the reliability of the RSM mathematical model in representing the actual interrelationships between the independent variables (starch, glycerol and guar gum) and the dependent variables (THI, D, WVP, TS, E, YM, PF and PD) of the pea starch based biodegradable edible films. The results of analysis of variance of the Box-Behnken design are given in Table 3 and Fig. 1. 
Fitting the model for thickness and density showed that $\mathrm{R}^{2}$ value of the models was 0.99 . The $p$ value for lack of fit, PRESS (predicted residual sum of square), F value and $p$-value of the model for thickness were $0.09,0.0003,122.95$ and $<0.0001$, respectively, and for density were 0.38 , $0.07,104.32$ and $<0.0001$, respectively. The results verified the reliability of the model in predicting thickness and density of films.

The RSM mathematical models for WVP were also calculated. The results (Fig. 1C) revealed $p$ values for WVP of $<0.0001$. Coefficient of determination $\left(\mathrm{R}^{2}\right)$ for the WVP model (Table 3 ) was estimated to be 1.00 , further specifying a close correlation between the predicted values and experimental values. Lack of fit value (0.066), PRESS value (23.91) and F value (247.35) showed that the mathematical model was successful predictor of WVP properties of the pea starch edible films.

In a similar manner, the results for mechanical properties: TS, \% E and YM also confirmed the competency of the model. The $\mathrm{R}^{2}$ values of TS, \% $\mathrm{E}$ and $\mathrm{YM}$ were $0.99,0.96$ and 0.99 , respectively (Fig. 1D-F). The $p$-values for lack of fit for all tensile mechanical parameters were found insignificant $(p>0.05$, Table 3$)$. The $p$-values $(0.99,0.86$ and 0.008 respectively), $\mathrm{F}$ values (134.98, 19.20 and 58.91 respectively) and PRESS values (11.87, 44.69 and 31394.02 respectively) of the model also supported the efficiency of these models in correctly evaluating the mechanical properties of pea starch edible films.

The RSM mathematical models for PF and PD were also calculated. The results (Fig. 1G and 1H) revealed $p$ values for PF and PD of $<0.0001$ and 0.0004 , respectively. Coefficient of determination $\left(\mathrm{R}^{2}\right)$ for the PF and PD models (Table 3) were estimated to be 0.99 and 0.96 , respectively, further specifying a close correlation between the predicted values and experimental values. PRESS 
values (36.51 and 11.58) and F values (122.15 and 18.85) showed that these mathematical models were successful predictors of puncture mechanical properties of the pea starch edible films.

The higher model F-values with low probability values $(p<0.0001)$ for all responses obviously specified that, the established models were significant to predict physical and mechanical characteristics of the films [4].

Empirical models were developed by applying multiple regression analysis on the experimental data obtained from BBD to represent an accurate correlation between independent variables and responses. The predicted responses expressed in terms of coded factors as follows:

THI $=0.13+0.02 x_{1}-0.003 x_{2}+0.10 x_{3}-0.0005 x_{1} x_{2}-0.0008 x_{1} x_{3}-0.0003 x_{2} x_{3}+$ $0.008 x_{1}^{2}+0.00005 x_{2}^{2}-0.0007 x_{3}^{2}$

$\mathrm{D}=1.72+0.35 x_{1}-0.02 x_{2}+0.07 x_{3}-0.012 x_{1} x_{2}+0.002 x_{1} x_{3}-0.011 x_{2} x_{3}-0.11 x_{1}^{2}+$ $0.017 x_{2}^{2}+0.02 x_{3}^{2}$

$\mathrm{WVP}=13.94+7.47 x_{1}+0.77 x_{2}+2.35 x_{3}+0.08 x_{1} x_{2}+0.78 x_{1} x_{3}+0.17 x_{2} x_{3}+2.24 x_{1}^{2}-$ $0.008 x_{2}^{2}+0.04 x_{3}^{2}$

$\mathrm{TS}=26.69+10.56 x_{1}-1.78 x_{2}+3.11 x_{3}+0.54 x_{1} x_{2}-1.57 x_{1} x_{3}+0.05 x_{2} x_{3}-4.09 x_{1}^{2}-$ $1.45 x_{2}^{2}-0.68 x_{3}^{2}$

$\mathrm{E}=15.15-3.94 x_{1}+1.04 x_{2}-4.17 x_{3}-0.30 x_{1} x_{2}+1.41 x_{1} x_{3}+0.33 x_{2} x_{3}+0.69 x_{1}^{2}+$ $0.48 x_{2}^{2}-0.39 x_{3}^{2}$

$\mathrm{YM}=170.63-115.17 x_{1}-25.12 x_{2}+70.13 x_{3}+0.61 x_{1} x_{2}+22.80 x_{1} x_{3}-20.71 x_{2} x_{3}+$ $0.82 x_{1}^{2}-12.40 x_{2}^{2}+26.77 x_{3}^{2}$ 


$$
\begin{aligned}
& \mathrm{PF}=19.489+11.947 x_{1}-1.160 x_{2}+3.947 x_{3}-0.770 x_{1} x_{2}+1.190 x_{1} x_{3}-0.593 x_{2} x_{3}+ \\
& 1.452 x_{1}^{2}-0.784 x_{2}^{2}+0.191 x_{3}^{2} \\
& \mathrm{PD}=6.740-1.725 x_{1}-0.769 x_{2}-1.725 x_{3}+0.027 x_{1} x_{2}-0.103 x_{1} x_{3}+0.098 x_{2} x_{3}- \\
& 0.318 x_{1}^{2}-0.049 x_{2}^{2}-0.027 x_{3}^{2}
\end{aligned}
$$

\subsection{The effect of independent variables on thickness}

Controlling of thickness is important for the barrier and mechanical characteristics of the ultimate film because this parameter can cause differences in the film structure by affecting the drying kinetics [40]. The data showed that the thickness of films had a positive correlation to the three experimental variables. Starch, glycerol and guar gum were all shown to have a significant influence on the film thickness. It was found that, thickness of film was increased from 0.110 to $0.162 \mathrm{~mm}$, owing to the increasing of starch, glycerol and guar content in the film forming solution. The dry matter of solutions increased because of the differences in film-forming solution formulations, which resulted in the differences in thickness of the films [4]. The increasing of thickness by increasing amount of starch and guar gum is attributed to the development of intermolecular hydrogen bonds between guar gum and starch, the content of dry matter and also interaction between polysaccharides [4]. The higher glycerol content, the more moisture absorbs resulting in increasing the thickness of the film because of swelling process [41]. The similar behavior has been reported by Jouki, Khazaei, Ghasemlou and HadiNezhad [42] and Ahmadi, Kalbasi-Ashtari, Oromiehie, Yarmand and Jahandideh [43]. The thickness increased slightly when glycerol amount was increased in film forming solution (Fig. 2 A-C). The incorporation of glycerol enhances the opportunity of interaction between the film polymers and glycerol and produces 
thicker films [4]. The interaction between independent variables starch $\times$ glycerol, starch $\times$ guar gum and glycerol $\times$ guar gum had no significant influence on the thickness $(p>0.05$, Table 4).

\subsection{The effect of independent variables on density}

The analysis of variance indicated that starch and guar gum level significantly $(p<0.05)$ affected the density of films (Table 4). The density of films as function of process variables are depicted in Fig. 2 (D-F). Guar gum forms strong inter-molecular interactions with pea starch and creates a compressed structure. Consequently, increase in guar gum and starch proportion with incorporation of glycerol causes increasing in film density [40]. Difference in density value is affected by molecular weight, composition and interaction components of the polymeric film structure [44].

The values of density obtained in this work was almost similar to that reported for cassava starch films [45], for cassava starch films and cassava starch-wheat bran composites [46] and for banana starch film [44].

\subsection{The effect of independent variables on water vapor permeability (WVP)}

Because of the role of water in deteriorative reactions in foods, moisture transfer between the food and surrounding atmosphere should be restricted [47]. Therefore, the WVP is extensively studied as the most important characteristic of edible films. The film structure, plasticizer, RH gradient and temperature of the environment affect this property [48]. All independent variables found to exert significant impact on the WVP $(p<0.05$, Table 4). Interaction between factors starch $\times$ guar gum was also shown to influence the WVP ( $p<0.05$, Table 4). The water vapor permeation through films is enhanced with the increase in concentration of guar gum and starch (Fig. 3 A-C). 
This behavior could be owing to their hydrophilicity nature and accessible hydroxyl groups which are capable to interact with water by hydrogen bonds. Thus, water molecules are more freely absorbed into the surface of the films (i.e., higher solubility) and permeate through the film structure more simply (i.e., higher diffusivity) bringing about the increase in WVP [37]. The addition of glycerol can make the film less compact by increasing the molecular mobility and enhancing free volume in the film network [49] and can increase the sorption of water. Prakash Maran, Sivakumar, Thirugnanasambandham and Sridhar [4] also observed a similar trend in maize starch and agar blend films. Maran, Sivakumar, Sridhar and Thirugnanasambandham [40] documented that tapioca starch films exhibited an increase in WVP with the increase of agar concentration.

\subsection{The effect of independent variables on tensile strength (TS)}

Table 4 shows that starch and guar gum have significant positive linear effects on TS, whereas, glycerol and its quadratic interaction have significant negative effects. The TS increased with increasing of starch and guar gum concentration, so the maximum TS was obtained with maximum value of starch and guar (Fig. 3 D-F). This is associated with the development of inter-molecular hydrogen bonds between guar and starch and also the cohesive molecular structure of the films which improved the tensile strength accordingly [50]. Other studies have reported that the addition of hydrocolloids increases the film mechanical strength [22, 40, 50-53]. The organized crystalline structure of the starch molecules is disordered by the gelatinization process that happens during film preparation, leading to the exposure of $-\mathrm{OH}$ groups that rapidly establish hydrogen bonds with the guar gum [54]. The maximum TS ranged from 6.61 MPa for film containing $2 \mathrm{~g}$ of starch, $0.1 \mathrm{~g}$ of guar and $25 \%$ glycerol to $34.10 \mathrm{MPa}$ for film with $3 \mathrm{~g}$ of starch, $0.5 \mathrm{~g}$ of guar and $25 \%$ glycerol. In the central point, the value was $26.70 \mathrm{MPa}$. The maximum TS of pea starch film with 
$70 \%$ glycerol conditioned at $23{ }^{\circ} \mathrm{C}$ and $50 \% \mathrm{RH}$ ranged from 2.65 to $4.32 \mathrm{MPa}$ [55]. Zhang and Han [56] reported maximum TS of 5.8 MPa for film obtained from $3 \%$ yellow pea starch and 20/50 w/w glycerol conditioned at $25{ }^{\circ} \mathrm{C}$ and $50 \% \mathrm{RH}$ for $72 \mathrm{~h}$. However, yellow pea starch films containing $3 \%$ starch and 40/60 w/w glycerol conditioned for $48 \mathrm{~h}$ at $50 \% \mathrm{RH}$ and $25{ }^{\circ} \mathrm{C}$ showed maximum TS of 2.3 MPa [57]. The observations regarding the effect of the glycerol content on the maximum TS are consistent with those found in literature. It has been documented that the incorporation of glycerol decreases the TS by interrupting direct interactions of the film-forming polymer [56, 58] resulting in decreasing the cohesiveness of the film network [22].

\subsection{The effect of independent variables on elongation at break (E)}

As can be inferred from the Table 4, E values were negatively affected by the linear terms of guar gum and starch contents. Figure 4 (A-C) represents the three-dimensional surface response plot of $\mathrm{E}$ as a function of the two independent variables calculated in this study. The highest $\mathrm{E}$ values of the composite film were obtained at the high concentration of glycerol and at the low concentration of guar gum. The synergism interaction between the guar gum and the pea starch influences the film elongation at break [59], inhibiting amylose-amylose interactions [60]. The more unfolded network, the weaker interaction forces and lower elongation at break performance will be [9]. The reduction of E may be explained by a binary hydrocolloid phase separation as a result of weakening gel structure by addition of guar gum to pea starch dispersion [9]. High temperature and shear force during the preparation of the starch films destroy the granular and crystalline structure of starch, promoting the presence of plasticizer into the matrix [50]. The development of hydrogen bonds between the hydroxyl groups of biopolymers and glycerol could reduce the links between nearby biopolymer chains, leading to improving flexibility of these chains and free volume between the nearby starch chains $[8,49]$. Similar results were observed by Bourtoom and Chinnan 
[54], Prakash Maran, Sivakumar, Thirugnanasambandham and Kandasamy [50], and da Matta, Sarmento, de Oliveira and Zocchi [22] for rice starch-chitosan, maize starch-agar, and pea starchxanthan composite films.

\subsection{The effect of independent variables on Young Modulus (YM)}

The YM signifies the stiffness of the film; a greater value attributes to a more stiff material [52]. The glycerol concentration had a negative effect on the YM values. On the other hand, the YM values were positively affected by the individual term of starch and guar gum, the interaction term of starch-guar gum, the quadratic term of guar gum, and negatively affected by the interaction guar gum-glycerol (Table 4). Subsequently, the YM values increased with the increase of the guar gum and with the decrease of the glycerol, which is in agreement with results that have been reported in the literature $[9,50,52,61,62]$. The pea starch films become more cohesive at higher guar gum proportions, causing greater resistance and higher Young's modulus. Increasing glycerol molecules cause reduction in Young's modulus of the films by disordering polymer alignment, increasing free volume and decreasing structural orientation in the polymeric system.

\subsection{The effect of independent variables on puncture mechanical properties}

Suitable mechanical strength and flexibility are commonly necessary for a packaging film to endure external stress and to preserve its stability along with barrier characteristics during applications in packaging [31]. The linear regression coefficients and their statistical significance are presented in Table 4. All the three independent process variables had significant effect on the puncture force $(\mathrm{PF})(p<0.05)$. The PF increased steadily when starch and guar gum increased; however, the levels of PF decreased when glycerol increased from $15 \%$ to $35 \%$ (Fig. 5 A-C), indicating the reinforcing influence of guar gum and the plasticizing effect of glycerol. These 
phenomena considerably depend on the distribution and quantity of inter- and intra-molecular associations [63]. These interactions was increased by enhancing the number of guar gum molecules, which consequently, imparted a stronger character to the film [62]. During gelatinization process, the organized structures of pea starch molecules are demolished, causing the exposure of $\mathrm{OH}$ groups to easily form hydrogen bonds with guar gum due to the chemical similarity of both polysaccharides [54]. On the other hand, the PF of composite films increased because of increasing the regions of the three-dimensional network structure formed by interaction between guar and pea starch chains [64].

The incorporation of glycerol noticeably decreased the PF. Glycerol is a relatively small hydrophilic molecule and could penetrate between starch chains and form hydrogen bonds with hydroxyl groups of starch. The direct interactions and the adjacency between starch chains were reduced by incorporation of glycerol in to the network [50]. Accordingly, under stress, movements of starch chains were accelerated and reduced the PF.

It can be noted that the linear coefficient of glycerol was positive, while the linear coefficients of pea starch and guar gum were negative for puncture deformation (PD) response. Interaction and quadratic regression coefficients did not show a significant impact on PD. Figure 5D-F demonstrates the contour plot of PD. It can be seen that an increasing proportion of glycerol, contributed to the increase of PD, while PD decreased as the pea starch and guar gum proportions simultaneously increased. Possibly, interaction between gum and starch chains through hydrogen bonds developed a more resistant network with lower flexibility behavior, making impossible the movement of polymeric chains [61]. A similar trend was observed by Prakash Maran, Sivakumar, Thirugnanasambandham and Kandasamy [50] who reported a significant and negative effect of the agar on PD of maize starch based edible films. 


\subsection{Optimization and validation of the models}

The simultaneous optimization of the multiple responses was determined based on the desirability function, which simultaneously optimizes the requirement for each response in the design by developing a mixture of independent variables [40]. The aim of this study was to maximize mechanical properties and to minimize WVP. Hence, these responses were selected to examine the possibility of considering one formulation which optimizes the characteristics of studied edible films. The desirability function was calculated by applying maximum, minimum, and average values of these variables experimentally obtained in the Box-Behnken experimental design (Table 2). The optimum level of pea starch of $2.5 \mathrm{~g}$, glycerol of $25 \%$, and guar gum of $0.3 \mathrm{~g}$ with an overall desirability of 0.75 was obtained according to the methodology of desired function.

The experimental validation of the above mentioned optimal conditions was implemented to prove the reliability of the models. The experimental results were compared with the predicted values of the responses with triplicate experiments (Table 5). The absolute residual error for the dependent variables ranged from $0.775 \%$ to $7.110 \%$, representing adequacy of the methodology established for the optimization of the process conditions, and reliability of the surface responses obtained by the Box-Behnken experimental design [23].

\section{Conclusion}

This study showed that the Box-Behnken response surface design (BBD) is an effective tool in evaluating the mechanical and barrier properties of edible films based on pea starch, glycerol, and guar gum. The results revealed that increasing starch and guar gum content favored formation of a more resistant polymeric structure with higher thickness, density, as well as water vapor permeability. Higher concentration of glycerol increased the flexibility and reduced the resistance 
and stiffness of the film. The optimal conditions for the production of a pea starch-guar gum edible film with good mechanical properties and low WVP were $2.5 \mathrm{~g}$ pea starch, $25 \% \mathrm{w} / \mathrm{w}$ glycerol and $0.3 \mathrm{~g}$ guar gum. It should be noted that impact of interaction between guar gum and pea starch on film formation is important; however the results were not presented in this paper due to the length limitation. These will be presented in another paper to enhance better understanding on the pea starch-guar gum film for utilization in food preservation and packaging.

\section{Acknowledgement}

This study was funded by the University of Newcastle, NSW Australia.

\section{Conflict of Interest}

The authors declare no conflict of interest.

\section{References}

[1] Andrade-Mahecha, M. M., Tapia-Blácido, D. R., Menegalli, F. C., Development and optimization of biodegradable films based on achira flour. Carbohyd. Polym. 2012, 88, 449-458.

[2] Šimkovic, I., Unexplored possibilities of all-polysaccharide composites. Carbohyd. Polym. 2013, 95, 697-715.

[3] Lopez, O., Garcia, M. A., Villar, M. A., Gentili, A., et al., Thermo-compression of biodegradable thermoplastic corn starch films containing chitin and chitosan. LWT - Food Sci.Technol. 2014, 57, 106-115. 
[4] Prakash Maran, J., Sivakumar, V., Thirugnanasambandham, K., Sridhar, R., Response surface modeling and analysis of barrier and optical properties of maize starch edible films. Int. J. Biol. macromol. 2013, 60, 412-421.

[5] Al-Hassan, A. A., Norziah, M. H., Starch-gelatin edible films: Water vapor permeability and mechanical properties as affected by plasticizers. Food Hydrocolloid. 2012, 26, 108-117.

[6] Mali, S., Grossmann, M. V. E., García, M. A., Martino, M. N., Zaritzky, N. E., Effects of controlled storage on thermal, mechanical and barrier properties of plasticized films from different starch sources. J. Food Eng. 2006, 75, 453-460.

[7] Veiga-Santos, P., Oliveira, L. M., Cereda, M. P., Scamparini, A. R. P., Sucrose and inverted sugar as plasticizer. Effect on cassava starch-gelatin film mechanical properties, hydrophilicity and water activity. Food Chem. 2007, 103, 255-262.

[8] Chang, Y. P., Abd Karim, A., Seow, C. C., Interactive plasticizing-antiplasticizing effects of water and glycerol on the tensile properties of tapioca starch films. Food Hydrocolloid. 2006, 20, $1-8$.

[9] Veiga-Santos, P., Oliveira, L. M., Cereda, M. P., Alves, A. J., Scamparini, A. R. P., Mechanical properties, hydrophilicity and water activity of starch-gum films: effect of additives and deacetylated xanthan gum. Food Hydrocolloid. 2005, 19, 341-349.

[10] Anker, M., Berntsen, J., Hermansson, A.-M., Stading, M., Improved water vapor barrier of whey protein films by addition of an acetylated monoglyceride. Innov. Food Sci. Emerg. Technol. 2002, 3, 81-92.

[11] Shekarabi, A. S., Oromiehie, A. R., Vaziri, A., Ardjmand, M., Safekordi, A. A., Investigation of the effect of nanoclay on the properties of quince seed mucilage edible films. Food Sci. Nutr. 2014, 2, 821-827. 
[12] Vásconez, M. B., Flores, S. K., Campos, C. A., Alvarado, J., Gerschenson, L. N., Antimicrobial activity and physical properties of chitosan-tapioca starch based edible films and coatings. Food Res. Int. 2009, 42, 762-769.

[13] Flores, S., Conte, A., Campos, C., Gerschenson, L., Del Nobile, M., Mass transport properties of tapioca-based active edible films. J. Food Eng. 2007, 81, 580-586.

[14] Phan The, D., Debeaufort, F., Voilley, A., Luu, D., Biopolymer interactions affect the functional properties of edible films based on agar, cassava starch and arabinoxylan blends. $J$. Food Eng. 2009, 90, 548-558.

[15] Achayuthakan, P., Suphantharika, M., Pasting and rheological properties of waxy corn starch as affected by guar gum and xanthan gum. Carbohyd. Polym. 2008, 71, 9-17.

[16] Yoshimura, M., Takaya, T., Nishinari, K., Effects of xyloglucan on the gelatinization and retrogradation of corn starch as studied by rheology and differential scanning calorimetry. Food Hydrocolloid. 1999, 13, 101-111.

[17] Veiga-Santos, P., Suzuki, C. K., Cereda, M. P., Scamparini, A. R. P., Microstructure and color of starch-gum films: Effect of gum deacetylation and additives. Part 2. Food Hydrocolloid. 2005, 19, 1064-1073.

[18] Bangyekan, C., Aht-Ong, D., Srikulkit, K., Preparation and properties evaluation of chitosancoated cassava starch films. Carbohyd. Polym. 2006, 63, 61-71.

[19] Lafargue, D., Lourdin, D., Doublier, J.-L., Film-forming properties of a modified starch/Кcarrageenan mixture in relation to its rheological behaviour. Carbohyd. Polym. 2007, 70, 101-111. [20] Chillo, S., Flores, S., Mastromatteo, M., Conte, A., et al., Influence of glycerol and chitosan on tapioca starch-based edible film properties. J. Food Eng. 2008, 88, 159-168. 
[21] Chen, C.-H., Lai, L.-S., Mechanical and water vapor barrier properties of tapioca starch/decolorized hsian-tsao leaf gum films in the presence of plasticizer. Food Hydrocolloid. 2008, 22, 1584-1595.

[22] da Matta, M. D., Sarmento, S. B. S., de Oliveira, L. M., Zocchi, S. S., Mechanical properties of pea starch films associated with xanthan gum and glycerol. Starch - Stärke 2011, 63, 274-282. [23] Saberi, B., Thakur, R., Vuong, Q. V., Chockchaisawasdee, S., et al., Optimization of physical and optical properties of biodegradable edible films based on pea starch and guar gum. Ind. Crop. Prod. 2016, 86, 342-352.

[24] Prajapat, A. L., Gogate, P. R., Intensification of depolymerization of aqueous guar gum using hydrodynamic cavitation. Chem. Eng. Process. 2015, 93, 1-9.

[25] Loock, E. E. M., The carob or locust tree, Ceratonia siliqua. J. S. Afr. Forest. Assoc. 1940, 4, 78.

[26] Butt, M. S., Shahzadi, N., Sharif, M. K., Nasir, M., Guar gum: a miracle therapy for hypercholesterolemia, hyperglycemia and obesity. Crit. Rev. Food Sci. Nutr. 2007, 47, 389-396.

[27] Kulicke, W.-M., Eidam, D., Kath, F., Kix, M., Kull, A. H., Hydrocolloids and Rheology: Regulation of Visco-elastic Characteristics of Waxy Rice Starch in Mixtures with Galactomannans. Starch - Stärke 1996, 48, 105-114.

[28] Whistler, R. L., BeMiller, J. N., Industrial Gums, Academic Press New York 1993.

[29] Saurabh, C. K., Gupta, S., Bahadur, J., Mazumder, S., et al., Mechanical and barrier properties of guar gum based nano-composite films. Carbohyd. Polym. 2015, 124, 77-84.

[30] Saurabh, C. K., Gupta, S., Bahadur, J., Mazumder, S., et al., Radiation dose dependent change in physiochemical, mechanical and barrier properties of guar gum based films. Carbohyd. Polym. 2013, 98, 1610-1617. 
[31] Rao, M. S., Kanatt, S. R., Chawla, S. P., Sharma, A., Chitosan and guar gum composite films: Preparation, physical, mechanical and antimicrobial properties. Carbohyd. Polym. 2010, 82, 1243 1247.

[32] Saurabh, C. K., Gupta, S., Variyar, P. S., Sharma, A., Effect of addition of nanoclay, beeswax, tween-80 and glycerol on physicochemical properties of guar gum films. Ind. Crop. Prod. 2016, $89,109-118$.

[33] Saberi, B., Vuong, Q., Chockchaisawasdee, S., Golding, J., et al., Water Sorption Isotherm of Pea Starch Edible Films and Prediction Models. Foods 2015, 5, 1.

[34] Larotonda, F. D. S., Matsui, K. N., Sobral, P. J. A., Laurindo, J. B., Hygroscopicity and water vapor permeability of Kraft paper impregnated with starch acetate. J. Food Eng. 2005, 71, 394402.

[35] E96-95, A., Standard Test Methods for Water Vapor Transmission of Material, American Society for Testing and Materials, Philadelphia, PA 1995.

[36] Gennadios, A., Weller, C. L., Gooding, C. H., Measurement errors in water vapor permeability of highly permeable, hydrophilic edible films. J. Food Eng. 1994, 21, 395-409.

[37] Saberi, B., Vuong, Q., Chockchaisawasdee, S., Golding, J., et al., Mechanical and physical properties of pea starch edible films in the presence of glycerol. J. Food Process. Preserv. 2015, In Press.

[38] ASTM, American Society for Testing and Materials. D882-00 2001.

[39] Bhuyan, D. J., Van Vuong, Q., Chalmers, A. C., van Altena, I. A., et al., Microwave-assisted extraction of Eucalyptus robusta leaf for the optimal yield of total phenolic compounds. Ind. Crop. Prod. 2015, 69, 290-299. 
[40] Maran, J. P., Sivakumar, V., Sridhar, R., Thirugnanasambandham, K., Development of model for barrier and optical properties of tapioca starch based edible films. Carbohyd. Polym. 2013, 92, 1335-1347.

[41] Jouki, M., Tabatabaei Yazdi, F., Mortazavi, S. A., Koocheki, A., Physical, barrier and antioxidant properties of a novel plasticized edible film from quince seed mucilage. Int. J. Biol. macromol. 2013, 62, 500-507.

[42] Jouki, M., Khazaei, N., Ghasemlou, M., HadiNezhad, M., Effect of glycerol concentration on edible film production from cress seed carbohydrate gum. Carbohyd. Polym. 2013, 96, 39-46.

[43] Ahmadi, R., Kalbasi-Ashtari, A., Oromiehie, A., Yarmand, M.-S., Jahandideh, F., Development and characterization of a novel biodegradable edible film obtained from psyllium seed (Plantago ovata Forsk). J. Food Eng. 2012, 109, 745-751.

[44] Pelissari, F. M., Andrade-Mahecha, M. M., Sobral, P. J. d. A., Menegalli, F. C., Comparative study on the properties of flour and starch films of plantain bananas (Musa paradisiaca). Food Hydrocolloid. 2013, 30, 681-690.

[45] Müller, C. M. O., Yamashita, F., Laurindo, J. B., Evaluation of the effects of glycerol and sorbitol concentration and water activity on the water barrier properties of cassava starch films through a solubility approach. Carbohyd. Polym. 2008, 72, 82-87.

[46] Famá, L., Gerschenson, L., Goyanes, S., Starch-vegetable fibre composites to protect food products. Carbohyd. Polym. 2009, 75, 230-235.

[47] Singh, T., Chatli, M., Sahoo, J., Development of chitosan based edible films: process optimization using response surface methodology. J. Food Sci. Technol. 2015, 52, 2530-2543. [48] Kurt, A., Kahyaoglu, T., Characterization of a new biodegradable edible film made from salep glucomannan. Carbohyd. Polym. 2014, 104, 50-58. 
[49] Mali, S., Grossmann, M. V. E., García, M. A., Martino, M. N., Zaritzky, N. E., Barrier, mechanical and optical properties of plasticized yam starch films. Carbohyd. Polym. 2004, 56, 129-135.

[50] Prakash Maran, J., Sivakumar, V., Thirugnanasambandham, K., Kandasamy, S., Modeling and analysis of film composition on mechanical properties of maize starch based edible films. Int. J. Biol. macromol. 2013, 62, 565-573.

[51] Bonilla, J., Atarés, L., Vargas, M., Chiralt, A., Properties of wheat starch film-forming dispersions and films as affected by chitosan addition. J. Food Eng. 2013, 114, 303-312.

[52] Pelissari, F. M., Yamashita, F., Garcia, M. A., Martino, M. N., et al., Constrained mixture design applied to the development of cassava starch-chitosan blown films. J. Food Eng. 2012, 108, 262-267.

[53] Shen, X. L., Wu, J. M., Chen, Y., Zhao, G., Antimicrobial and physical properties of sweet potato starch films incorporated with potassium sorbate or chitosan. Food Hydrocolloid. 2010, 24, 285-290.

[54] Bourtoom, T., Chinnan, M. S., Preparation and properties of rice starch-chitosan blend biodegradable film. LWT - Food Sci.Technol. 2008, 41, 1633-1641.

[55] Liu, L., Kerry, J. F., Kerry, J. P., Selection of optimum extrusion technology parameters in the manufacture of edible/biodegradable packaging films derived from food-based polymers. $J$. Food Agric. Environ. 2005, 3, 51-58.

[56] Zhang, Y., Han, J. H., Mechanical and thermal characteristics of pea starch films plasticized with monosaccharides and polyols. J. Food Sci. 2006, 71, 109-118.

[57] Han, J. H., Seo, G. H., Park, I. M., Kim, G. N., Lee, D. S., Physical and Mechanical Properties of Pea Starch Edible Films Containing Beeswax Emulsions. J. Food Sci. 2006, 71, 290-296. 
[58] Mali, S., Grossmann, M. V. E., García, M. A., Martino, M. N., Zaritzky, N. E., Mechanical and thermal properties of yam starch films. Food Hydrocolloid. 2005, 19, 157-164.

[59] Katzbauer, B., Properties and applications of xanthan gum. Polym. Degradation Stab. 1998, $59,81-84$.

[60] Navarro, A. S., Martino, M. N., Zaritzky, N. E., Viscoelastic properties of frozen starchtriglycerides systems. J. Food Eng. 1997, 34, 411-427.

[61] Arismendi, C., Chillo, S., Conte, A., Del Nobile, M. A., et al., Optimization of physical properties of xanthan gum/tapioca starch edible matrices containing potassium sorbate and evaluation of its antimicrobial effectiveness. LWT - Food Sci.Technol. 2013, 53, 290-296.

[62] Flores, Costa, D., Yamashita, F., Gerschenson, L. N., Grossmann, M. V., Mixture design for evaluation of potassium sorbate and xanthan gum effect on properties of tapioca starch films obtained by extrusion. Materials Science and Engineering: C 2010, 30, 196-202.

[63] Espinel Villacres, R. A., Flores, S. K., Gerschenson, L. N., Biopolymeric antimicrobial films: study of the influence of hydroxypropyl methylcellulose, tapioca starch and glycerol contents on physical properties. Mater. Sci. Eng.: C 2014, 36, 108-117.

[64] Wu, Y., Geng, F., Chang, P. R., Yu, J., Ma, X., Effect of agar on the microstructure and performance of potato starch film. Carbohyd. Polym. 2009, 76, 299-304. 


\section{Figure captions}

Figure 1. Correlations between predicted and experimental thickness (A), density (B), water vapor permeability (C), tensile strength (D), percent elongation at break (E). Young modulus (F), puncture force $(\mathrm{G})$, and puncture deformation $(\mathrm{H})$.

Figure 2. Response surface plots showing the interaction effects of process variables on thickness (A-C) and density (D-F).

Figure 3. Response surface plots showing the interaction effects of process variables on WVP(AC) and tensile strength (D-F).

Figure 4. Response surface plots showing the interaction effects of process variables on percent elongation at break (A-C) and Young modulus (D-F).

Figure 5. Response surface plots showing the interaction effects of process variables on puncture force value (A-C) and puncture deformation value (D-F). 
Table 1. Independent variables and their code variable levels used for the Box-Behnken design.

\begin{tabular}{cccc}
\hline \multirow{2}{*}{$\begin{array}{c}\text { Coded variable } \\
\text { levels }\end{array}$} & \multicolumn{3}{c}{ Independent variables } \\
\cline { 2 - 4 } & Pea starch $(\mathbf{g})$ & Glycerol $(\%$ w/w) & Guar gum $(\mathbf{g})$ \\
\hline+1 & 2 & 15 & 0.1 \\
0 & 2.5 & 25 & 0.3 \\
-1 & 3 & 35 & 0.5 \\
\hline
\end{tabular}


1 Table 2. Box-Behnken experimental design with process variables (un-coded) and observed responses.

\begin{tabular}{|c|c|c|c|c|c|c|c|c|c|c|c|}
\hline Run & $\begin{array}{l}\text { Starch } \\
\text { (g) }\end{array}$ & $\begin{array}{l}\text { Glycerol } \\
(\% \text { w/w })\end{array}$ & $\begin{array}{c}\text { Guar gum } \\
\text { (g) }\end{array}$ & $\begin{array}{c}\text { THI } \\
(\mathbf{m m})\end{array}$ & $\begin{array}{c}\mathbf{D} \\
\times 10^{-3} \\
\left(\mathrm{gmm}^{-3}\right) \\
\end{array}$ & $\begin{array}{c}\text { WVP } \\
\times 10^{-10} \\
\left(\mathrm{gPa}^{-1} \mathbf{s}^{-1} \mathrm{~m}^{-1}\right) \\
\end{array}$ & $\begin{array}{c}\text { TS } \\
(\mathbf{M P a})\end{array}$ & $\begin{array}{c}\mathbf{E} \\
(\%)\end{array}$ & $\begin{array}{c}\text { YM } \\
(\mathbf{M P a})\end{array}$ & $\begin{array}{l}\mathbf{P F} \\
(\mathbf{N})\end{array}$ & $\begin{array}{c}\text { PD } \\
(\mathbf{m m})\end{array}$ \\
\hline 1 & 2 & 25 & 0.1 & 0.110 & 1.225 & 6.702 & 6.605 & 25.372 & 26.049 & 6.935 & 9.927 \\
\hline 2 & 2 & 15 & 0.3 & 0.119 & 1.229 & 8.161 & 12.863 & 19.216 & 68.305 & 8.129 & 7.459 \\
\hline 3 & 2 & 35 & 0.3 & 0.122 & 1.281 & 9.367 & 8.449 & 21.218 & 40.172 & 7.881 & 8.870 \\
\hline 4 & 2 & 25 & 0.5 & 0.128 & 1.366 & 10.673 & 15.999 & 13.525 & 119.356 & 11.842 & 6.175 \\
\hline 5 & 2.5 & 15 & 0.1 & 0.115 & 1.680 & 11.368 & 23.417 & 18.033 & 130.278 & 15.479 & 7.426 \\
\hline 6 & 2.5 & 35 & 0.1 & 0.121 & 1.708 & 12.721 & 19.538 & 20.134 & 98.136 & 13.812 & 8.842 \\
\hline 7 & 2.5 & 25 & 0.3 & 0.131 & 1.720 & 13.674 & 26.695 & 15.155 & 177.636 & 18.949 & 6.776 \\
\hline 8 & 2.5 & 25 & 0.3 & 0.129 & 1.740 & 13.851 & 27.240 & 13.226 & 170.960 & 21.049 & 5.878 \\
\hline 9 & 2.5 & 25 & 0.3 & 0.129 & 1.680 & 13.971 & 24.698 & 14.281 & 172.945 & 18.093 & 7.661 \\
\hline 10 & 2.5 & 25 & 0.3 & 0.128 & 1.700 & 14.173 & 28.057 & 17.353 & 161.682 & 18.705 & 6.788 \\
\hline 11 & 2.5 & 25 & 0.3 & 0.130 & 1.760 & 14.046 & 26.783 & 15.759 & 169.959 & 20.648 & 6.594 \\
\hline 12 & 2.5 & 15 & 0.5 & 0.136 & 1.775 & 14.875 & 29.496 & 9.698 & 313.304 & 25.165 & 4.288 \\
\hline 13 & 2.5 & 35 & 0.5 & 0.143 & 1.850 & 16.935 & 25.809 & 13.112 & 198.307 & 21.127 & 6.098 \\
\hline 14 & 3 & 25 & 0.1 & 0.147 & 1.882 & 20.218 & 30.988 & 14.552 & 231.499 & 28.042 & 6.820 \\
\hline 15 & 3 & 15 & 0.3 & 0.152 & 1.997 & 22.816 & 32.757 & 12.052 & 276.732 & 33.973 & 3.820 \\
\hline 16 & 3 & 35 & 0.3 & 0.157 & 2.001 & 24.321 & 30.517 & 12.842 & 251.020 & 30.643 & 5.339 \\
\hline 17 & 3 & 25 & 0.5 & 0.162 & 2.032 & 27.295 & 34.101 & 8.364 & 415.998 & 37.708 & 2.655 \\
\hline
\end{tabular}

$2 \quad$ "THI:Thickness; D: Density; WVP: Water vapor permeability; TS: Tensile strength; E: Elongation at break; YM: Young modulus; PF: Puncture force; PD: Puncture 3 deformation. 
6 Table 3. Analysis of variance for determination of model fitting.

\begin{tabular}{|c|c|c|c|c|c|c|c|c|}
\hline $\begin{array}{c}\text { Sources of } \\
\text { variation }\end{array}$ & $\begin{array}{c}\text { THI } \\
(\mathbf{m m})\end{array}$ & $\begin{array}{c}\text { D } \\
\times 10^{-3} \\
\left(\mathrm{gmm}^{-3}\right)\end{array}$ & $\begin{array}{c}\text { WVP } \\
\times 10^{-10} \\
\left(\mathrm{gPa}^{-1} \mathbf{s}^{-1} \mathrm{~m}^{-1}\right)\end{array}$ & $\begin{array}{c}\text { TS } \\
(\mathbf{M P a})\end{array}$ & $\begin{array}{c}\mathrm{E} \\
(\%)\end{array}$ & $\begin{array}{c}\mathbf{Y M} \\
(\mathbf{M P a})\end{array}$ & $\begin{array}{l}\text { PF } \\
(\mathbf{N})\end{array}$ & $\begin{array}{c}\text { PD } \\
(\mathbf{m m})\end{array}$ \\
\hline Lack of fit & 0.096 & 0.377 & 0.066 & 0.992 & 0.855 & 0.088 & 0.806 & 0.721 \\
\hline $\mathrm{R}^{2}$ & 0.993 & 0.992 & 0.997 & 0.994 & 0.961 & 0.987 & 0.994 & 0.960 \\
\hline Adjusted $\mathrm{R}^{2}$ & 0.986 & 0.983 & 0.993 & 0.987 & 0.911 & 0.970 & 0.990 & 0.909 \\
\hline PRESS & 0.0003 & 0.071 & 23.910 & 11.866 & 44.688 & 31394.02 & 36.514 & 11.576 \\
\hline F ratio of model & 122.95 & 104.32 & 247.35 & 134.98 & 19.20 & 58.91 & 122.149 & 18.849 \\
\hline$p$ of model $>\mathrm{F}$ & $<0.0001^{*}$ & $<0.0001^{*}$ & $<0.0001^{*}$ & $<0.0001^{*}$ & $0.0004^{*}$ & $<0.0001^{*}$ & $<0.0001^{*}$ & $0.0004^{*}$ \\
\hline
\end{tabular}

$7 *$ Significant difference with $p<0.05$. 
9 Table 4. Analysis of variance for the experimental results.*

\begin{tabular}{|c|c|c|c|c|c|c|c|c|c|c|c|c|c|c|c|c|c|}
\hline \multirow[b]{2}{*}{$\mathbf{P}$} & \multirow[b]{2}{*}{ DF } & \multicolumn{2}{|c|}{ THI } & \multicolumn{2}{|c|}{ D } & \multicolumn{2}{|c|}{ WVP } & \multicolumn{2}{|c|}{ TS } & \multicolumn{2}{|c|}{$\mathbf{E}$} & \multicolumn{2}{|c|}{$\mathbf{Y M}$} & \multicolumn{2}{|c|}{$\mathbf{P F}$} & \multicolumn{2}{|c|}{ PD } \\
\hline & & Estimate & $\begin{array}{c}\text { Prob> } \\
|t|\end{array}$ & Estimate & $\begin{array}{c}\text { Prob> } \\
|t|\end{array}$ & Estimate & $\begin{array}{c}\text { Prob> } \\
|t|\end{array}$ & Estimate & $\begin{array}{c}\text { Prob> } \\
|t|\end{array}$ & Estimate & $\begin{array}{c}\text { Prob> } \\
|t|\end{array}$ & Estimate & $\begin{array}{c}\text { Prob> } \\
|t|\end{array}$ & Estimate & $\begin{array}{c}\text { Prob> } \\
|t|\end{array}$ & Estimate & $\begin{array}{c}\text { Prob> } \\
|t|\end{array}$ \\
\hline$\beta_{0}$ & 1 & 0.13 & $<.0001^{*}$ & 1.72 & $<.0001^{*}$ & 13.94 & $<.0001^{*}$ & 6.740 & $<.0001^{*}$ & 170.64 & $<.0001^{*}$ & 26.69 & $<.0001^{*}$ & 15.15 & $<.0001^{*}$ & 170.64 & $<.0001^{*}$ \\
\hline$\beta_{1}$ & 1 & 0.02 & $<.0001^{*}$ & 0.35 & $<.0001^{*}$ & 7.47 & $<.0001^{*}$ & -1.725 & $<.0001^{*}$ & 115.17 & $<.0001^{*}$ & 10.56 & $<.0001^{*}$ & -3.94 & $<.0001^{*}$ & 115.17 & $<.0001^{*}$ \\
\hline$\beta_{2}$ & 1 & 0.003 & $0.0041^{*}$ & 0.02 & 0.1412 & 0.77 & $0.0028^{*}$ & 0.769 & $0.0059^{*}$ & -25.12 & $0.0059^{*}$ & -1.78 & $0.0011^{*}$ & 1.04 & 0.0559 & -25.12 & $0.0045^{*}$ \\
\hline$\beta_{3}$ & 1 & 0.01 & $<.0001^{*}$ & 0.07 & $0.0009^{*}$ & 2.35 & $<.0001^{*}$ & -1.725 & $<.0001^{*}$ & 70.12 & $<.0001^{*}$ & 3.11 & $<.0001^{*}$ & -4.17 & $<.0001^{*}$ & 70.12 & $<.0001^{*}$ \\
\hline$\beta_{12}$ & 1 & 0.0005 & 0.5899 & -0.01 & 0.5018 & 0.08 & 0.7613 & 0.027 & 0.9253 & 0.61 & 0.9253 & 0.54 & 0.2891 & -0.30 & 0.6511 & 0.61 & 0.9460 \\
\hline$\beta_{13}$ & 1 & -0.0007 & 0.4250 & 0.002 & 0.8981 & 0.78 & $0.0147^{*}$ & -0.103 & 0.7226 & 22.80 & 0.7226 & 1.57 & $0.0129^{*}$ & 1.41 & 0.0633 & 22.80 & $0.0333^{*}$ \\
\hline$\beta_{23}$ & 1 & 0.0003 & 0.7858 & 0.01 & 0.5105 & 0.17 & 0.4943 & 0.099 & 0.7345 & -20.71 & 0.7345 & 0.05 & 0.9222 & 0.33 & 0.6247 & -20.71 & $0.0447^{*}$ \\
\hline$\beta_{11}$ & 1 & 0.0081 & $<.0001^{*}$ & -0.11 & $0.0003^{*}$ & 2.24 & $<.0001^{*}$ & -0.318 & 0.2801 & 0.82 & 0.2801 & 4.09 & $<.0001^{*}$ & 0.69 & 0.3044 & 0.82 & 0.9250 \\
\hline$\beta_{22}$ & 1 & 0.00005 & 0.9554 & 0.02 & 0.3377 & -0.01 & 0.9743 & -0.049 & 0.8616 & -12.40 & 0.8616 & -1.45 & $0.0162^{*}$ & 0.48 & 0.4642 & -12.40 & 0.1838 \\
\hline$\beta_{33}$ & 1 & -0.0007 & 0.4440 & 0.02 & 0.3581 & 0.04 & 0.8565 & -0.027 & 0.9237 & 26.77 & 0.9237 & -0.68 & 0.1865 & -0.39 & 0.5481 & 26.77 & $0.0154^{*}$ \\
\hline
\end{tabular}

$10 \quad{ }^{*}$ Significantly different at $p<0.05$; P: parameter; $\beta_{0}$ : intercept; $\beta_{1}, \beta_{2}$, and $\beta_{3}$ : linear regression coefficients for pea starch, glycerol and 11 guar gum; $\beta_{12}, \beta_{13}$, and $\beta_{23}$ : regression coefficients for interaction between starch $\times$ glycerol, starch $\times$ guar gum and glycerol $\times$ guar gum;

$12 \beta_{11}, \beta_{22}$, and $\beta_{33}$ : quadratic regression coefficients for starch $\times$ starch, glycerol $\times$ glycerol, guar gum $\times$ guar gum. 
14 Table 5. Results of experimental validation of the optimal conditions for the development of pea

15 starch-guar gum edible film.*

\section{Experimental}

\begin{tabular}{|c|c|c|c|}
\hline Responses & Predicted value & $\begin{array}{l}\text { value } \\
(n=3)^{a}\end{array}$ & $\begin{array}{c}\text { Absolute residual } \\
\text { error }(\%)^{\mathbf{b}}\end{array}$ \\
\hline Thickness (mm) & $0.130 \pm 0.007^{\mathrm{a}}$ & $0.129 \pm 0.042^{\mathrm{a}}$ & 0.775 \\
\hline Density $\times 10^{-3}\left(\mathrm{gmm}^{-3}\right)$ & $1.727 \pm 0.638^{\mathrm{a}}$ & $1.712 \pm 0.323^{\mathrm{a}}$ & 0.876 \\
\hline $\mathrm{WVP} \times 10^{-10}\left(\mathrm{gPa}^{-1} \mathrm{~s}^{-1} \mathrm{~m}^{-1}\right)$ & $14.085 \pm 1.112^{\mathrm{a}}$ & $13.874 \pm 1.107^{\mathrm{a}}$ & 1.521 \\
\hline Tensile strength $(\mathrm{MPa})$ & $26.901 \pm 2.366^{\mathrm{a}}$ & $27.792 \pm 2.204^{\mathrm{a}}$ & 3.206 \\
\hline Elongation at break $(\%)$ & $15.077 \pm 1.252^{\mathrm{a}}$ & $16.231 \pm 1.732^{\mathrm{a}}$ & 7.110 \\
\hline Young modulus (MPa) & $172.910 \pm 20.751^{\mathrm{a}}$ & $175.683 \pm 14.163^{\mathrm{a}}$ & 1.578 \\
\hline Puncture force $(\mathrm{N})$ & $19.725 \pm 2.469^{\mathrm{a}}$ & $20.315 \pm 1.521^{\mathrm{a}}$ & 2.904 \\
\hline Puncture deformation (mm) & $6.707 \pm 0.505^{\mathrm{a}}$ & $7.100 \pm 1.004^{\mathrm{a}}$ & 5.535 \\
\hline
\end{tabular}

